\title{
Assessment of an Energy-Efficient Aircraft Concept from a Techno-Economic Perspective
}

\author{
C. Goldberg, D. Nalianda, V. Sethi, P. Pilidis and R. Singh \\ Cranfield University, Bedfordshire, United Kingdom \\ K. Kyprianidis \\ Mälardalen University, Västerås, Sweden
}

\section{Abstract}

An increase in environmental awareness in both the aviation industry and the wider global setting has led to large bodies of research dedicated to developing more sustainable technology with a lower environmental impact and lower energy usage. The goal of reducing environmental impact has necessitated research into revolutionary new technologies that have the potential to be significantly more energy efficient than their predecessors. However, for innovative technologies in any industry, there is a risk that adoption will be prohibitively expensive for commercial application. It is therefore important to model the economic factors of the new technology or policy at an early stage of development.

This research demonstrates the application of a Techno-economic Environmental Risk Assessment framework that may be used to identify the economic impact of an energy-efficient aircraft concept and the impact that environmental policy would have on the viability of the concept. The framework has been applied to a case study aircraft designed to achieve an energy saving of $60 \%$ in comparison to a baseline 2005 entry-into-service aircraft. The model compares the green aircraft concept to a baseline conventional aircraft using a sensitivity analysis of the aircraft direct operating cost to changes in acquisition and maintenance cost.

The research illustrates an economically viable region for the technology. Cost margins are identified where the increase in operating cost due to expensive novel technology is counterbalanced by the reduction in cost resulting from low energy consumption. Viability was found to be closely linked to fuel price, with a low fuel price limiting the viability of energy-efficient aviation technology. In contrast, a change in environmental taxation policy was found to be beneficial, with the introduction of carbon taxation incentivising the use of an environmentally optimised aircraft.

Keywords: Techno-economics, Green aviation, Alternative fuels

\section{Nomenclature}




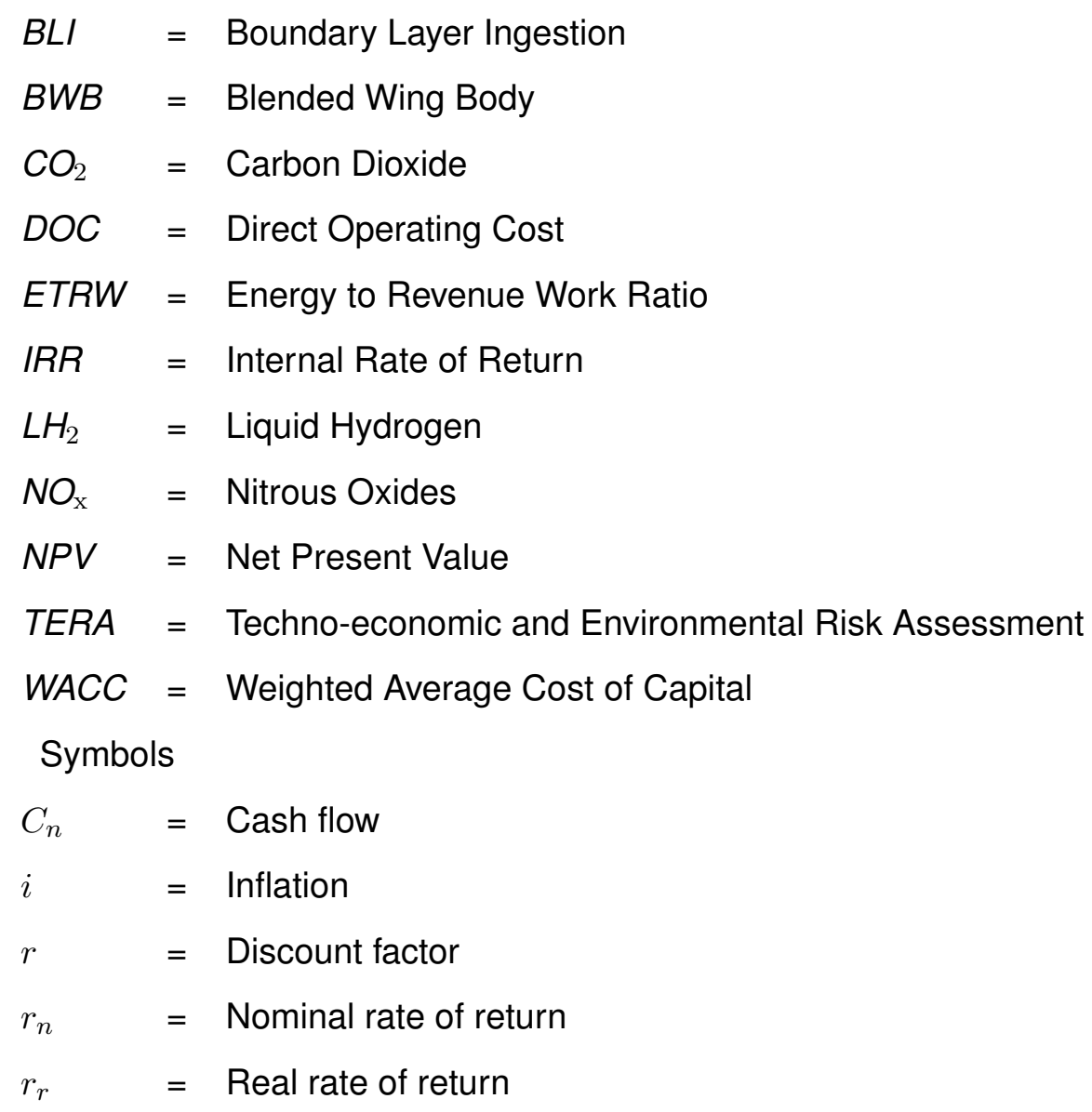

\section{Introduction}

The aviation industry can be considered a key contributor to today's global economy and has grown continuously since its inception. Modern aircraft - whilst superficially similar - are significantly more energy efficient and produce significantly less environmental pollutants than their predecessors. Despite accounting for only approximately $2 \%$ of total global Carbon Dioxide emissions [1], the impact of aviation will become increasingly noticeable as other industries such as power generation and road transport move towards low emission and green technologies. The aviation industry has therefore become increasingly aware of the environmental impact of its growth and now aims for a more sustainable future. Historically, the primary focus of the development of new technology has been on decreasing fuel consumption. Nevertheless, with the current growth of the aviation industry, emissions and energy consumption will continue to increase unless action is taken, particularly in sectors with large air traffic growth such as China [2]. In order to drive the development of greener aviation, The civil aerospace industry has set for itself challenging goals for future aircraft in the mid to long term timeframe. The focus of these goals is to achieve dramatic reductions in the emission of Carbon Dioxide, Nitrous Oxides \& noise and to reduce the industry's overall energy consumption. Current development 
suggests that these targets are unachievable with the typically evolutionary nature of new technology. Revolutionary new technologies and policy changes are therefore required to enable a more sustainable aviation industry. However, the introduction of a change in technologies and policies poses a high risk, particularly in an industry such as aviation where development and certification requires the investment of large sums of time and money.

Given the risk inherent in the development of new technology, it is then useful to forecast the economic impact of a new technology at the early stages of development. Most studies focused on the development of new technology generally assess concepts from a pure performance perspective. However, commercial decisions are made principally and primarily based on economic factors. Goel and Rich [3] highlighted that a significant operating cost difference is the main incentive for adoption of new technology. Historically, high fuel prices have encouraged operators to push for improvements in energy efficiency as the penalty of operating older, less efficient aircraft is high. As fuel costs often contribute in the region of $40 \%$ to the operating cost of an aircraft [4], the development of greener technology may run in line with cost reduction goals. As fuel is a significant portion of operating cost, Kristjanpoller and Concha identify that fluctuations in oil price correlate closely with an airline's profitability, where an increase in oil price is followed by an increase in stock price [5]. However, fuel is not the sole operating cost for an aircraft. It is therefore vital to establish the overall economic benefits and commercial viability of new technologies and policies, a type of study rather rarely seen.

Given all these factors, it is vital to have a framework for assessing the economic aspects of a design at the preliminary phase. This combines both technological aspects, in terms of the ability to meet performance targets such as fuel burn, emissions, or noise levels, and the economic viability, in terms of manufacturer and operator costs. This techno-economic perspective is then used to inform design decisions or determine viability. The techno-economic studies by Mavris et al. provide this perspective by presenting novel technology in terms of a metric with a corresponding impact on factors such as performance and cost [6]. Technoeconomics can also be used to help determine aviation policies that will encourage investment in an aviation concept. In a study to predict the $\mathrm{CO}_{2}$ taxation level to encourage investment in new aircraft, Dray et al. [7] highlight the interdependencies of different factors, as a change in policy or the introduction of new technology may have a wider ranging effect. The wider effect of technology infusion was also assessed in a study by Tam et al. [8]. The study highlighted that policy decisions will influence profitability of a novel technology and that there is a wider context that may need to be considered in the course of developing a revolutionary aircraft.

Factors such as maintenance, crew salary and insurance are major contributing factors to 
an aircraft's operating cost. Edwards et al. present a combined optimisation perspective for reducing the $\mathrm{CO}_{2}$ emissions of an in-service aircraft using the aircraft Cost Index [9], the ratio between the unit cost of time and fuel. However, they identify that time costs have a more significant impact on cost than fuel-related costs, even once emissions taxation is introduced. A similar conclusion is drawn by Nalianda et al. when assessing the economic viability of a novel propulsion system concept [10]. Given the predominance of time and ownership-related costs, a reduction in fuel consumption provided by a change in operation or new technology can be quickly outweighed by rising costs elsewhere. It therefore becomes difficult for an operator to justify investment in the novel energy efficient technology. Newnes identifies that the general expectation is that $70-80 \%$ of program costs are committed at the early concept phase [11]. This highlights the importance of identifying the costs and benefits of novel technology at an early stage of development. Without including cost, a highly efficient aircraft may be prohibitively expensive to purchase, discouraging adoption regardless of performance improvements.

Research on revolutionary aircraft concepts predominantly focuses on performance simulation and defining propulsion system or aircraft configurations. As a result, there is limited research that attempts to identify the financial benefit of the energy efficient concepts currently under investigation. It was therefore necessary to develop a way to present performance benefits in a form suitable for a financier's perspective: translation of improved energy efficiency to higher operating cost benefits and a greater return on investment. The goal of the method in the present research is to quantify the financial value of a revolutionary environmentally optimised energy efficient technology. The focus herein is on a case-study of the NASA N3-X conceptual aircraft, developed by Felder et al. $[12,13]$. Establishing the economic viability of a concept is vital to ensure an environmentally and economically sustainable industry. Two key questions must therefore be answered for the N3-X: What is the financial value of efficiency improvements offered by the novel technologies of the aircraft? Secondly, in what situations or scenarios would the aircraft be financially viable?

This research will therefore address the techno-economic and environmental risk assessment aspects of a novel aircraft such as the N3-X. The present study aims to demonstrate a method that can present technology benefits in a form suitable for financiers and decision makers of the commercial aviation industry. As there is significant uncertainty in predicting the cost of a novel aircraft, a reverse approach to the economic viability question has been used [10]. Rather than predicting a cost for the aircraft and then assessing financial benefits, maximum cost boundaries can be identified, beyond which there is no longer any financial benefit for an operator to adopt the technology. The core goal of the research is to provide a method 


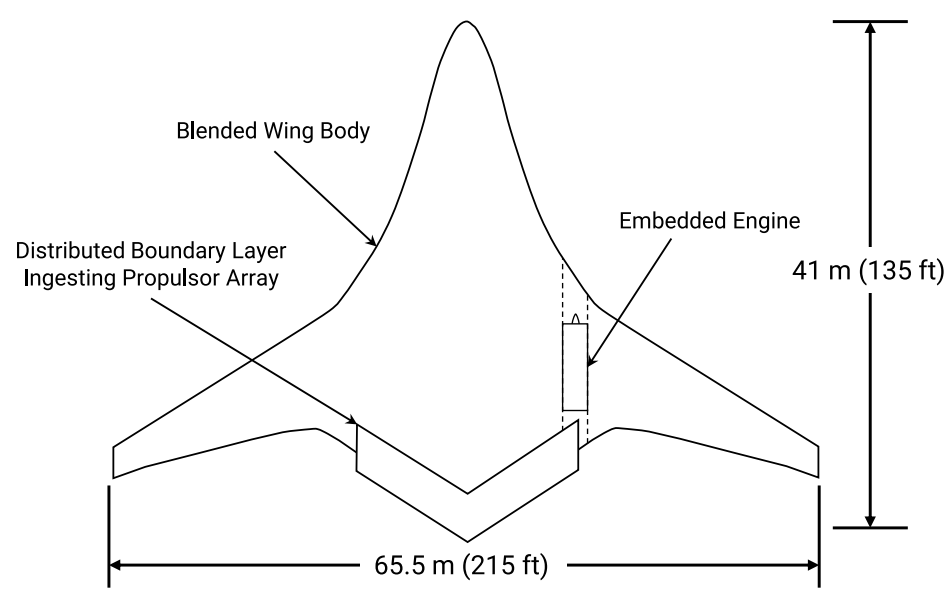

Figure 1: Top-down sketch of the N3-X blended wing body aircraft.

that enables the identification of economically viable cost for a new aviation technology and the influence that environmental policy decisions can have over the adoption of green aviation technology. The method may therefore be used to support the selection process between a range of green aviation technologies.

The focus of the research is on NASA's N3-X aircraft, a green aircraft concept targeted to achieve their $\mathrm{N}+3$ goals for $2035+(60 \%$ energy saving versus a 2005 baseline aircraft, amongst other goals). The concept makes use of a number of novel technologies not yet introduced in commercial aviation. The N3-X is a blended wing body aircraft (BWB) with a distributed propulsion system, powered by a pair of turbogenerators through a superconducting electrical system [12]. Such hybridised and turboelectric systems have been shown to offer significant energy consumption benefits versus conventional aircraft propulsion system [13, 14].

Alternative fuel types may also be considered as replacement options for kerosene to support the reduction of environmental pollutants. One such option is liquid hydrogen $\left(\mathrm{LH}_{2}\right)$. The use of $\mathrm{LH}_{2}$ eliminates the production of Carbon Dioxide and - as a high energy density fuel - offers a more energy optimised solution [15]. In addition, the water products of $\mathrm{LH}_{2} \mathrm{com}$ bustion will increase the production of contrails, an additional factor to aviation emissions that has been identified as contributing to climate change [16]. In addition, the low density of liquid hydrogen limits the range of an aircraft due to volume-based maximum fuel capacity limitations $[17,18]$. Nevertheless, $\mathrm{LH}_{2}$ aircraft propulsion would lead to a dramatic reduction in aviation's $\mathrm{CO}_{2}$ emissions footprint and could potentially reduce the use of hydrocarbons.

\section{Methodology}

The research makes use of an existing techno-economic and environmental risk assessment (TERA) framework that combines the technological and economic performance of a novel 
technology [10]. TERA is a multi-disciplinary framework for predicting the performance of new technologies or policies which may also be applied to obtain optimised solutions. TERA can simulate performance (aircraft and/or engine), economics, environmental impact, noise, emissions and cost in a modular framework [19].

The framework consists of a set of core modules which allow for detailed simulation of novel propulsion systems with physics-based component models. The core modules can be further linked with a wide range of environment, economic, and risk modules. The system assessments are conducted on a whole aircraft and mission level and may be used to deliver an insight into the relative risks and benefits of promising but uncertain concepts in the early stages of development. The framework allows for an increased visibility of risks, whilst enabling the user to compare and rank competing schemes on a formal and consistent basis, such that investment resources may be efficiently allocated [20, 21, 22]. In a similar manner to the content of this research, TERA has been used to assess concepts that may be suitable for greener propulsion and aviation, and the policy or market conditions that would provide a more favourable economic environment for the aircraft. For example, in the techno-economic assessment of a counter-rotating open rotor concept it was shown that despite relatively significant fuel savings of $25-29 \%$, an operating cost benefit of only $5-10 \%$ resulted [10]. Such research demonstrates the necessity of the integration of an economic perspective at an early stage, where future market changes may render a conceptual technology economically nonviable. TERA has been used extensively in the past to conduct design space exploration and trade-off, parameter sensitivity analysis, asset management and multi-disciplinary optimisation studies [22, 23, 24].

The N3-X aircraft concept has been considered from a techno-economic perspective in order to assess its economic viability. Previous studies have established that the N3-X is capable of achieving the targets set in the N+3 subsonic fixed wing aircraft goals [12, 13, 25], hence, this study will attempt to assess the economic viability aspect of the aircraft. The first half of the work consisted of creating a performance model for the technology with comparison to the B777-200LR as a baseline. This baseline is consistent with NASA's work on the aircraft and was selected as per the definition of NASA's Subsonic Fixed Wing goals [13].

The TERA assessment of the aircraft follows the framework shown in Figure 2 . In order to model the economics of the novel aircraft, a performance model must first be created. For the baseline aircraft, this consists of an aircraft performance model combined with an engine performance model to create a model approximating the B777-200LR (i.e. a 2005 entry into service aircraft). The novel configuration of the N3-X necessitates a modelling approach that 


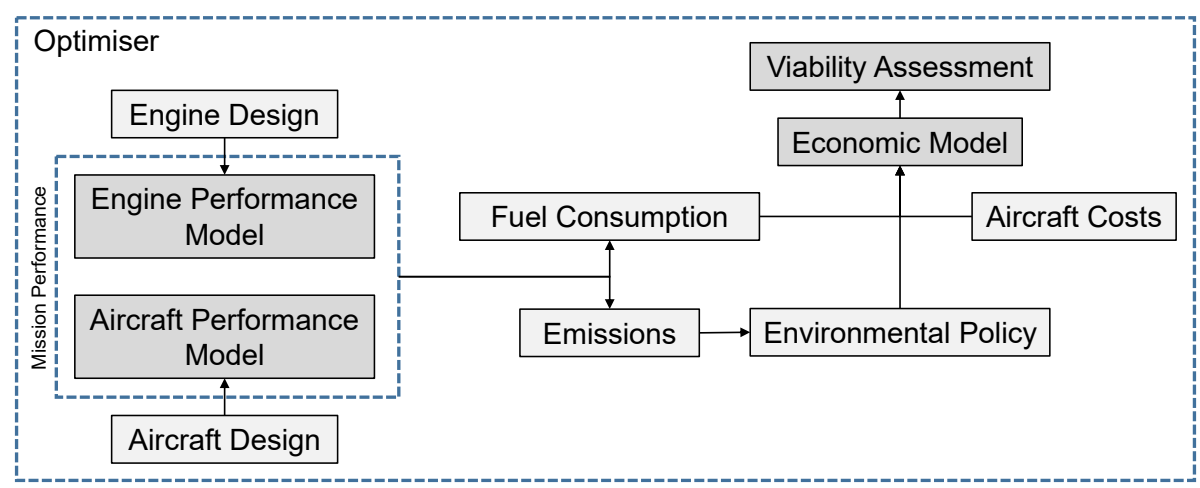

Figure 2: Schematic of TERA framework.

combines a module to simulate the distributed boundary layer ingesting propulsor array, the power-producing engines, and the aircraft. These modules are described briefly in the following subsections.

\subsection{Propulsor Array Model}

Performance of the boundary layer ingesting propulsion system was predicted from an integrated net propulsive force perspective. The inlet flow characteristics were estimated as a mass averaged value over the entire inlet stream. The performance of the propulsion array was subsequently calculated using one-dimensional gas dynamics methods. Off design performance of the integrated propulsion system was calculated in a similar manner by iterating the streamtube size [26]. This was done in order to match the flow demanded by the fan, resulting in a varying proportion of ingested free stream and boundary layer flow. The propulsors were assumed to have a variable area nozzle [12]. Fan mass flow, efficiency, and pressure ratio at alternative power settings were determined from a scaled fan map.

\subsection{Engine Model (Turbomachinery)}

The engines for both the baseline aircraft and the N3-X were modelled using in-house gas turbine software, Turbomatch [27]. Turbomatch is a legacy gas turbine performance simulation and diagnostics software developed by Cranfield University. The modelling software is based on zero-dimensional analysis of the aero-thermodynamic processes occurring throughout the engine gas path, employing discrete component maps. The incorporated methodology essentially solves for the mass and energy balance between the various engine components. The modelling software has been previously deployed in several studies for the prediction of design point, off-design and transient performance of gas turbine engines. Turbomatch offers performance simulations ranging from simple steady state (design point and off design) simulations to complex transient performance calculations for conventional, novel and conceptual cycles [28]. 
The performance model is based on typical gas turbine performance simulation modelling assumptions for fluid thermodynamic properties. Dedicated fluid property tables (i.e. specific enthalpy, entropy function, gamma, gas constant and dynamic viscosity as functions of temperature and fuel to air ratio) have been incorporated for air, products of combustion of Jet-A1 and air. At the level of zero-dimensional performance simulations, the combustor module takes the combustor inlet conditions (mass flow, temperature and pressure, obtained from the upstream component), the fuel temperature, the combustion efficiency and the pressure loss through the combustor as inputs.

The propulsive power for the baseline aircraft is provided by a pair of twin spool turbofan engines. The performance of the engines was matched to public domain data available for the GE90-115B turbofan engines[29]. The main engines of the N3-X are required to provide power for the aircraft propulsor array through a superconducting electrical system. The engines are therefore primarily power producing, although a small amount of core nozzle thrust is produced to counteract the engine drag. Power requirements are defined by the propulsor array. Each of the two main gas turbine power units of the N3-X was assumed to produce half of the total required power, including a slight excess to account for the $99.8 \%$ transmission efficiency [13].

\subsection{Aircraft Model}

Conventional aircraft mission simulation tools are designed to support standard aircraft configurations and propulsion systems. However, there are a limited number of tools available to enable the simulation and integration of the novel propulsion system architecture of the N3-X. Therefore, a custom aircraft performance model was created for this study, in order to appropriately combine conventional aircraft simulation methods with a module to suitably simulate a novel and highly integrated propulsion system [30]. The mission performance model applied a point mass approximation of the aircraft with a drag module to estimate the drag of both a conventional tube-and-wing and a BWB. Block fuel burn was estimated by splitting the aircraft mission into taxi, take-off, climb, cruise, descent, and landing segments. No improvements to air traffic management were assumed for 2035. The aircraft therefore cruise at a fixed altitude. In addition, block fuel includes reserve fuel for a $200 \mathrm{nmi}$ diversion to an alternate airport, plus an additional reserve of $5 \%$ total fuel weight (FAR Pt.121).

The baseline aircraft model was created using publicly available dimensions and scale drawings of the aircraft, with key figures detailed in Table 2 [31, 32]. The aircraft's design range is 7500 nautical miles and is modelled in a 3-class 301 passenger configuration. Weights and dimensions for the N3-X were obtained from referenced sources[12, 13, 25] in combination with a 3-D model of the aircraft available in the public domain [33] (Table 2). For the $\mathrm{LH}_{2}$ aircraft, fuel 
Table 2: Key aircraft dimensions and weights.

\begin{tabular}{lcc}
\hline Parameter & Baseline & N3-X \\
\hline \multicolumn{3}{c}{ Dimensions } \\
\hline $\begin{array}{l}\text { Fuselage Length (m) } \\
\text { Fuselage Diameter (m) }\end{array}$ & 63.7 & 40.5 \\
Wing Span (m) & 64.8 & N/A \\
Effective Aspect Ratio & 8.75 \\
\hline \multicolumn{3}{c}{ Weights } \\
\hline \multirow{3}{c}{15.96} \\
\hline OEW (kg) & 155,530 & 121,470 \\
Max. Payload Mass (kg) & 53,570 & 53,570 \\
\hline
\end{tabular}

must be stored in special pressurised tanks, with the maximum capacity of the aircraft limited by the space available for cylindrical fuel tanks in the belly of the aircraft. The low density of $\mathrm{LH}_{2}$ limits the maximum fuel load that the $\mathrm{LH}_{2}$ aircraft can carry to a significantly lower amount than the weight of fuel carried by kerosene aircraft. The $\mathrm{LH}_{2}$ fuel tank weight was estimated using a model that accounts for the structural weight, the mass of the insulating foam required to maintain the fuel at the required temperature (approximately $20 \mathrm{~K}$ ) and the tank liner required to prevent permeation of the fuel through the tank wall [34, 35].

\subsection{Economic Investment Cost Analysis Model}

The first step in predicting economic performance of a project is the estimation of the operating cost. Operating cost may be split into two components, direct and indirect [4]. Direct costs can be easily associated with a project, such as materials or labour. Indirect costs are typically more difficult to attribute to a single project, and will include administrative staff salaries and similar miscellaneous costs which may be distributed over a range of projects. Indirect costs are a necessary component of company-wide assessment, but in the case of a single project or proposal, the direct operating costs (DOC) will be more applicable.

For the present study, the project in question is the purchase and operation of a new green aviation concept from the perspective of an airline operator. Costs related to such a project are therefore the purchase, ownership, and running costs of an aircraft. The direct operating cost of an aircraft is primarily due to three factors:

- Performance (Fuel and emissions cost)

- Acquisition price (Interest, insurance, and depreciation)

- Maintenance cost 


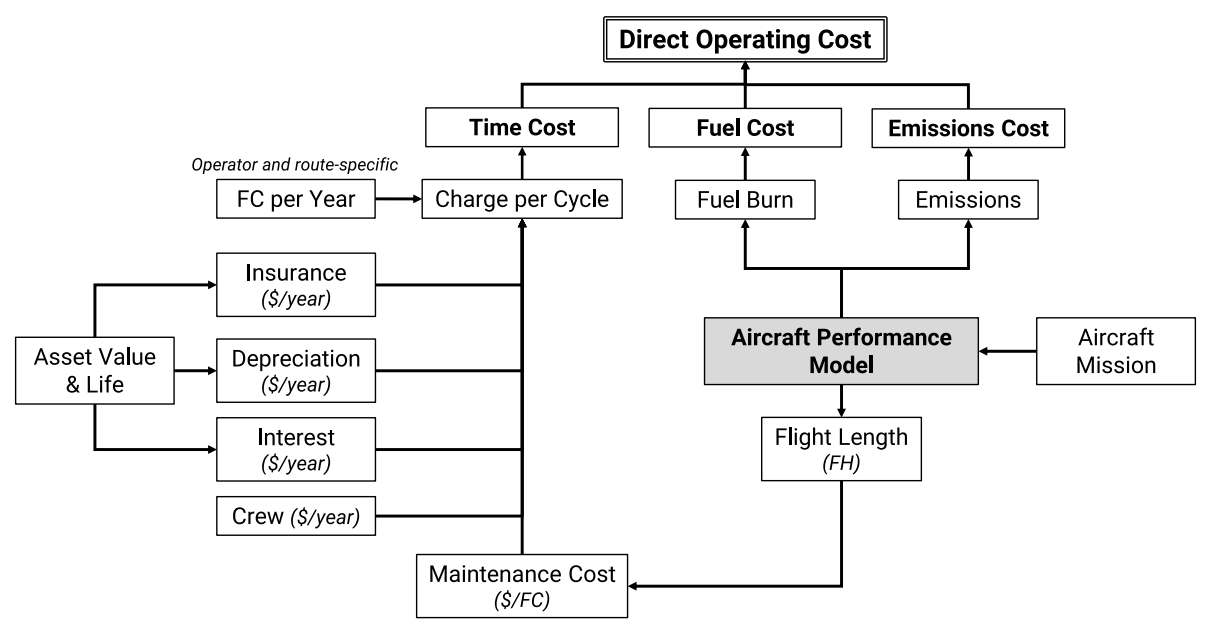

Figure 3: Breakdown of direct operating cost model components for an aircraft ownership model

For a novel aircraft, performance costs may be derived from aircraft performance modelling. However, acquisition price and maintenance cost are uncertain at the preliminary design stage. In this case, direct operating cost has been split into three sub-components: time, fuel, and emissions cost. Fuel and emissions costs are inter-related, with both being a function of the aircraft energy efficiency, fuel consumption, and engine characteristics. Both costs can be estimated using the output of aircraft performance models. Introducing an emissions cost component enables the simulation of alternate future policy scenarios, such as carbon taxation. The time cost component consists of costs associated with the purchase and ownership of an aircraft, including insurance cost, crew salary, interest, depreciation and maintenance. These costs combine to predict the operating cost of the aircraft per mission/flight cycle (Figure 3).

Investment cost analyses are often performed to assist in project and investment decisions. Rather than simply totalling the predicted costs and revenue of a project over its life, it is more common to make use of Net Present Value (NPV). The NPV concept takes into account the fact that incomes or expenditures in the future have less impact than the same values now. In order to represent this, NPV weights a project's profit and loss by making use of a discount factor. Often the interest rate is used as a discount factor. The weighted average cost of capital (WACC) may also be used, a parameter which weights the costs a company attributes to debt and equity. This discount factor represents the return on investment that would be required to exceed the return achieved by investing the money elsewhere.

The NPV of a project can be calculated according to Equation 1, where $C_{n}$ is the cash flow in each year of the project or product life cycle.

$$
\mathrm{NPV}=\sum_{n=0}^{\text {life }} \frac{\mathrm{C}_{\mathrm{n}}}{(1+r)^{n}}
$$

When comparing a selection of project investments, the one offering the highest NPV is the 
one most likely to be selected. An alternative way of assessing the suitability of a project is to calculate the Internal Rate of Return (IRR). This value is the rate for which the project NPV breaks even, i.e. expenditures exactly cancel out income. The higher this value of IRR, the greater the return on investments provided by the project. A project should ideally exceed the minimum required return rate in order to be considered a suitable investment [36]. This minimum may be represented by the WACC, around 7-8\% in the airline industry [37].

The effect of inflation can be included in the calculation by either modifying the cash flow or the rate of return. In the first case, the cash flow, $C_{n}$, in each time step of the calculation is inflated using the current inflation rate and discounted using a money or nominal rate of return. In the second case, the cash flow is left in terms of the real cash flow value at the project start, and the inflation correction is applied to the discount factor to obtain a real rate of return [38]. Including inflation becomes increasingly relevant in the case of projects with long life cycles. In the present study, the real cash flow and rate of return will be used. Therefore, the inflation rate is accounted for within the rate of return term, whilst the cash flow values are in terms of the value of money at the start of the project. The nominal (inflation independent) rate of return may be calculated from the real term using the following formula [38]:

$$
\left(1+r_{n}\right)=\left(1+r_{r}\right)(1+i)
$$

Where $r_{n}$ and $r_{r}$ are the nominal and real rates of return, respectively, and $i$ is the inflation rate.

For this assessment, the NPV analysis is made in terms of the difference in operating cost between the baseline aircraft and N3-X, as no revenue assumptions have been made. An initial conclusion can then be drawn as to whether the new aircraft is more profitable than the alternative baseline aircraft. Subsequently, the project IRR is calculated based on this DOC difference in order to assess whether it exceeds the WACC [10]. This leads to a NPV formulation as follows:

$$
\Delta X=\sum_{n=1}^{\text {life }} \frac{\Delta \mathrm{DOC}}{(1+\mathrm{IRR})^{n}}
$$

In this formulation, $\Delta X$ is equal to the difference in initial investment (i.e. the difference in aircraft purchase cost), $\triangle \mathrm{DOC}$ is the difference in direct operating cost, and IRR is the real rate of return for which the project NPV is equal to zero.

A map relating direct operating cost to acquisition and maintenance cost can be created using the method of Figure 4. The formulation helps in identifying how operating cost is influenced by aircraft purchase and ownership costs. A manufacturer can subsequently identify the maximum aircraft cost that would be acceptable for a commercial proposal at an early stage. In addition, it can be used to predict how economic viability might be influenced by a changing economic environment and new policies. In the case where the required maximum maintenance 


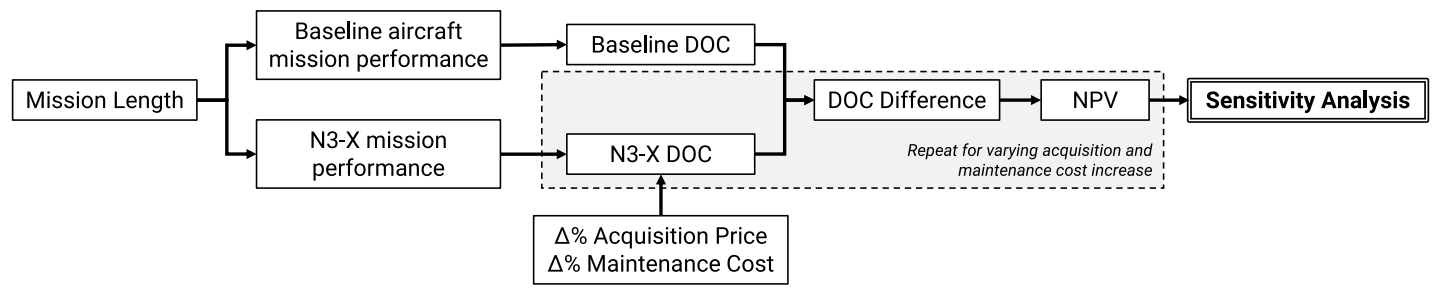

Figure 4: Flowchart for direct operating cost sensitivity analysis

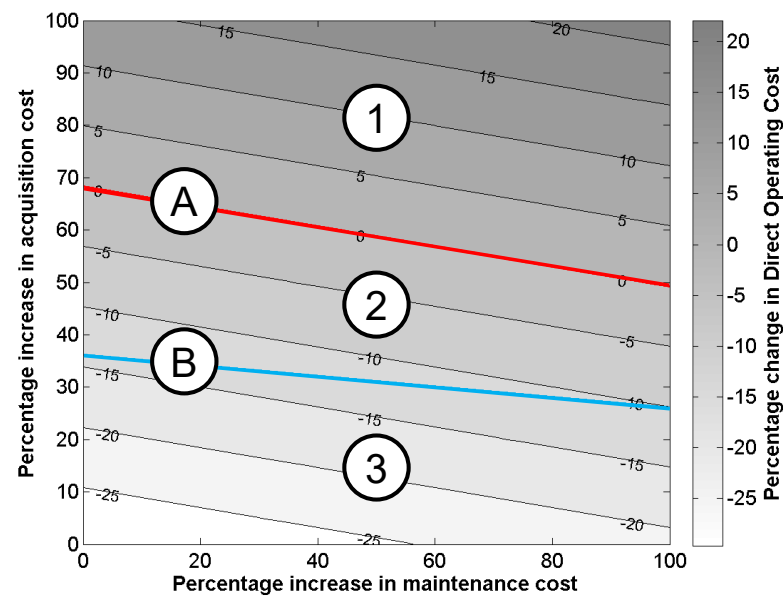

(1) Non-profitable

(2) Profitable, inadequate IRR

(poor return on investment)

(3) Profitable, suitable IRR

(good return on investment)

(A) No change in DOC

(B) $I R R=W A C C$

Figure 5: Sample economic model output

and acquisition costs are unattainable, a suitably favourable economic environment (with particular focus on fuel price or emissions taxation) can be determined as a component of policy development. Figure 5 presents a sample representation of the techno-economic calculation, consisting of three distinct regions marked by the two indicated trend lines.

Modules were included to adjust the yearly flight cycles per year based on flight cycle length. An aircraft flying predominately short haul missions is typically limited by the number of flight hours flown, whilst a long haul aircraft will be limited to a maximum number of cycles. A trend was created from reference data between hours flown per year and cycles per year in order to approximate this relationship and model the change in operation of the aircraft [39]. Maintenance cost was scaled on a severity curve to approximate the increased cost associated with operating an aircraft on many short cycles as opposed to the lower cost of operating fewer long cycles.

\section{Results and Discussion}

\subsection{Mission Performance}

The key aspect of the performance component of the research is to compare the energy consumption of the aircraft in comparison to the baseline. This assessment was performed 


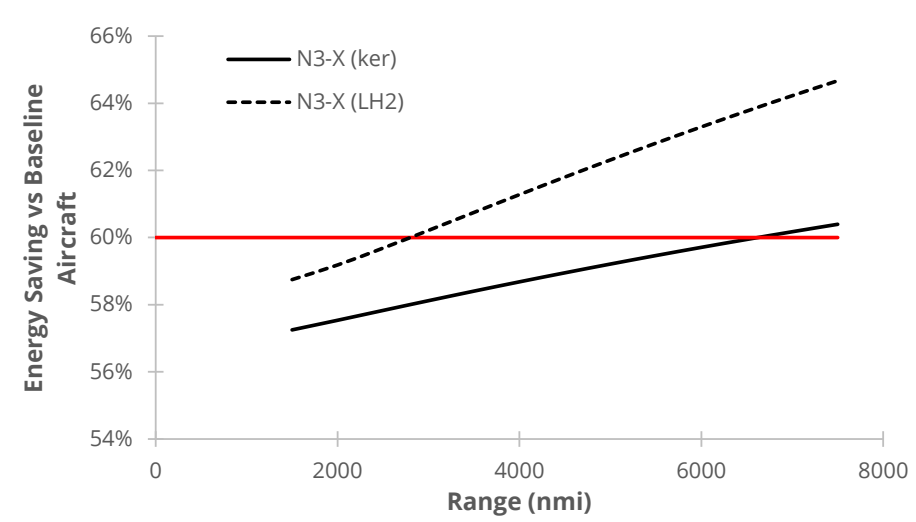

Figure 6: N3-X mission energy saving in comparison to the baseline (60\% saving target marked)

by estimating the mission performance of the aircraft over a range of flight lengths. From an energy perspective, in the case of the kerosene fuelled N3-X, the energy saving is equal to the fuel saving, with a corresponding reduction in $\mathrm{CO}_{2}$ emissions. NASA's N+3 goals for subsonic fixed wing aircraft target an energy/fuel consumption saving of $60 \%$ in comparison to the baseline aircraft. Simulation of the aircraft suggests it will achieve an energy saving of $60.4 \%$ in comparison to the baseline aircraft for the design mission (Figure 6). As the $\mathrm{LH}_{2}$ variant is lighter during the course of a flight, it is able to achieve a higher energy saving versus the baseline aircraft.

The reasons for the perceived performance increase of the N3-X versus the baseline may be identified by inspecting a number of aircraft efficiency indicators. From an airframe consideration, the lift-to-drag ratio of the simulated N3-X is approximately 25, in comparison to 19 for the baseline. The specific fuel consumption of the simulated N3-X propulsion system (fuel consumed per unit thrust) is $10.3 \mathrm{mg} / \mathrm{Ns}$, in comparison to the $15.8 \mathrm{mg} / \mathrm{Ns}$ of the baseline engines. These factors, combined with the lower weight of the N3-X, combine to create an aircraft that simulations suggest will be significantly more efficient than the selected baseline.

It should be noted that the defined baseline is a 2005 entry-into-service aircraft, as required by the developmental targets for the aircraft. Development in aviation is already moving towards greener technologies with a corresponding increase in energy saving. Energy savings versus a conventional aircraft with a 2035 entry-into-service will be lower. Nonetheless, the technologies presented in the N3-X would appear to offer large fuel burn and hence emission benefits over the baseline aircraft. This suggests that the technologies implemented are suitable for achieving the energy saving required for the industry and as defined in the $\mathrm{N}+3$ developmental goals. However, as has been identified in the introduction, energy efficiency alone is not an adequate measure for the viability of a concept. Instead it is necessary to assess the economic impact of new technology adoption on an operator in the aviation industry. An economic analysis is 
required to identify whether a saving in energy consumption translates into a saving in cost.

\subsection{Investment Cost Analysis Results}

In commercial aircraft operation, the end result of a more efficient aircraft is ideally a reduction in direct operating cost. This goal is typically achieved by developing technologies that reduce energy use (and emissions in an emission taxation scenario). However, novel technology has a high likelihood of being more expensive to develop and own than conventional aircraft, necessitating an investment cost analysis. For the sensitivity analysis, the baseline acquisition cost was obtained from Boeing's quoted list price for the B777-200LR as $\$ 318.3$ mil (2015). Maintenance cost per flight hour for the B777-200LR were obtained from collected reference data [39, 40]. Kerosene fuel price has been taken from IATA's fuel monitor for July 2017 as $\$ 477.2$ per metric tonne $(60.6 \$ / \mathrm{bbl})$.

\subsubsection{Kerosene N3-X}

As an initial point of comparison, the N3-X was initially assumed to have a $0 \%$ increase in acquisition and maintenance cost in comparison to the B777-200LR. This allowed the datum operating cost of the kerosene N3-X to be compared to the operating cost of the B777-200LR, with the sole difference being the change in fuel consumption. The operating cost was estimated for a selection of mission ranges up to the design payload range of the baseline aircraft (Figure 7). For the design mission, fuel contributes to approxiamtely $36 \%$ of the baseline aircraft's direct operating cost. Therefore, the $60.04 \%$ fuel saving of the N3-X leads to a $21.1 \%$ reduction in direct operating cost, assuming all other costs remain equal. As the mission range reduces, the net difference in fuel consumption reduces and fuel contributes less to the total direct operating cost (Figure 8). At short ranges, the main expense is the cost of repaying the aircraft purchase cost and the value lost as the aircraft depreciates. Therefore, the potential direct operating cost saving is lower for shorter range missions.

For lower fuel prices, fuel will contribute less to the total direct operating cost of the baseline aircraft. The direct operating cost saving offered by a high efficiency aircraft is therefore lower. This reinforces previous conclusions that the number of new aircraft purchases falls with reducing fuel prices, as it becomes hard to justify the purchase of a high efficiency aircraft when fuel costs are low. It is therefore more difficult to incentivise the adoption of greener technologies due to limited commercial benefits. The fuel saving offered by the N3-X can come to the fore where fuel costs and fuel consumption is high. As fuel price increases, the percentage contribution of fuel to the total DOC increases, and hence the DOC benefit presented by the aircraft will increase. Likewise, taxation on emissions (a factor not present in this first simulated scenario), 


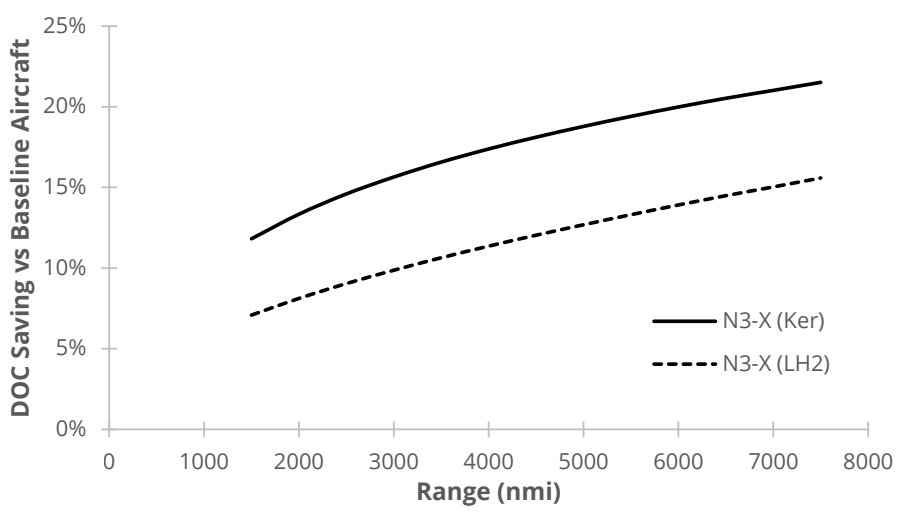

Figure 7: Direct operating cost comparison for the N3-X and baseline aircraft (assuming acquisition and maintenance equal to the baseline)

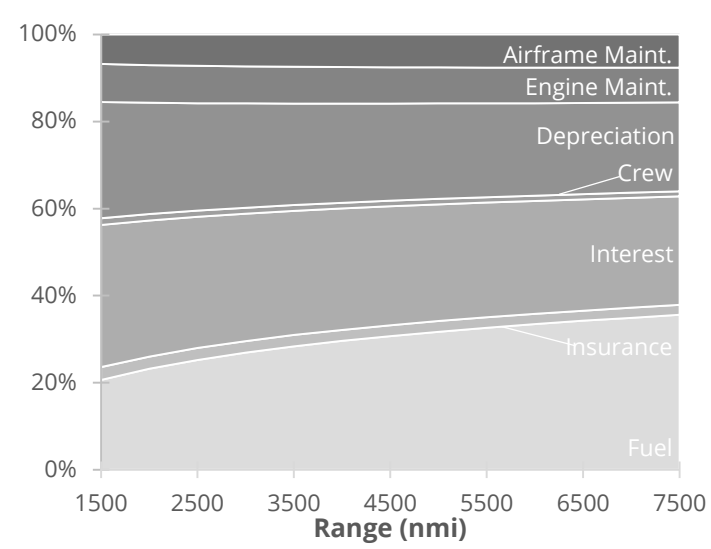

(a) Baseline Aircraft

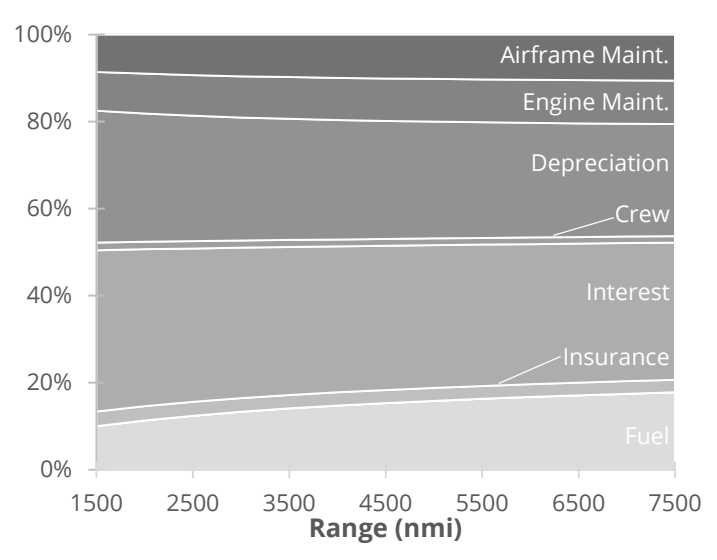

(b) N3-X (Kerosene)

Figure 8: Components of direct operating cost per flight for baseline and N3-X aircraft (assuming equal acquisition and maintenance costs).

would increase the performance-related cost impact of fuel usage on DOC and encourage the adoption of more energy efficient and environmentally friendly options.

Assuming that the acquisition and maintenance cost of the N3-X will differ to that of the baseline aircraft, the percentage contribution of fuel price on operating costs is further reduced, with greater costs being attributed to th other cost components of the aircraft in comparison to the baseline. The previously described operating cost sensitivity analysis was performed in order to identify how this influences commercial viability. Two sample missions were selected: 2500 and 7500 nautical miles, to represent medium- and long-haul missions for the aircraft (Figure 9).

As might be expected, the operating cost benefits decrease as the maintenance cost and acquisition price increase. Despite large savings in fuel, the high aircraft acquisition and maintenance cost of the aircraft is the most significant contributing factor to its operation. In scenarios where the aircraft is utilised on shorter range flights, there is very little margin for increase in 


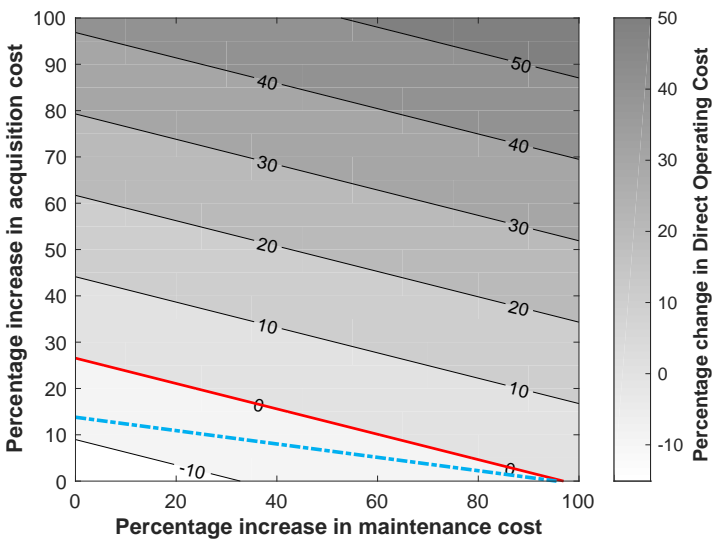

(a) 2500 nmi mission.

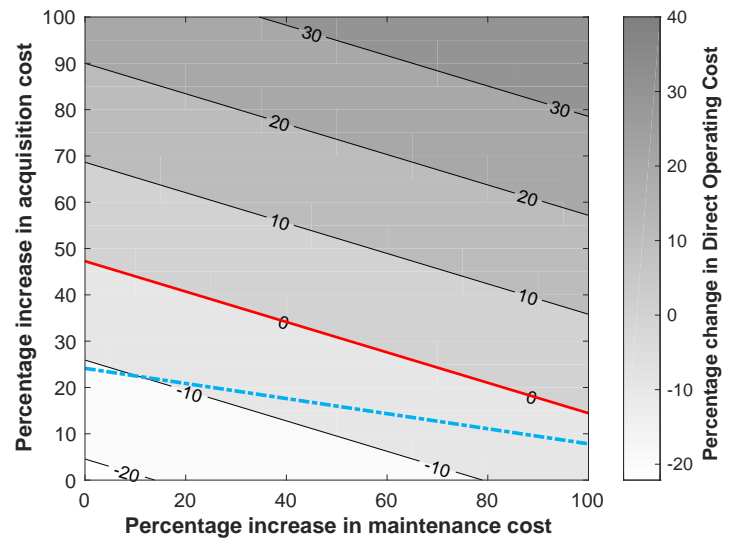

(b) 7500 nmi mission.

Figure 9: Direct operating cost sensitivity analysis for the kerosene N3-X in comparison to the baseline aircraft

cost before the aircraft becomes more expensive to operate than the baseline. As the mission range increases, fuel cost becomes a greater factor and hence the margin for cost increases widens, supporting the viability of energy efficient concepts. For the design 7500 nautical mission, the maximum acquisition price to ensure an attractive investment for operators is $24 \%$ greater than the baseline aircraft. However, at this price, the aircraft would not be attractive for an operator looking for an aircraft for flights in the 2500 nautical mile region.

It is interesting to note that there is a more significant margin for an increase in maintenance cost than acquisition cost. Although maintenance cost for the N3-X is likely to be a more significant cost than fuel costs, there is also a benefit to aiming for low acquisition price rather than low maintenance cost. Acquisition price of the aircraft links to the largest components of the direct operating cost: depreciation and insurance. In addition, the acquisition price of the aircraft is a sunk cost once the aircraft has been purchased. An operator also has slightly more control over an aircraft or propulsion systems maintenance costs, such as by improving maintenance practice or by modifying aircraft/engine operation. This suggests that high complexity (high maintenance) options with a low acquisition price are more economically viable than low complexity (low maintenance), high acquisition price options.

The previous analysis was performed using a fuel price that is comparatively low when observing fuel prices in the 2010-2015 time-frame. However, historical fuel price trends and the limited and volatile nature of hydrocarbon sources highlight the importance of considering a higher fuel price for a 2035 entry aircraft. In addition to changes in fuel price, policy changes such as carbon taxation on aviation emissions should be considered. Further assessments were therefore performed to consider two alternative scenarios. Figure 10a shows the simulation of a scenario with a fuel price 1.5 times that of the initial assessment (possible within the 


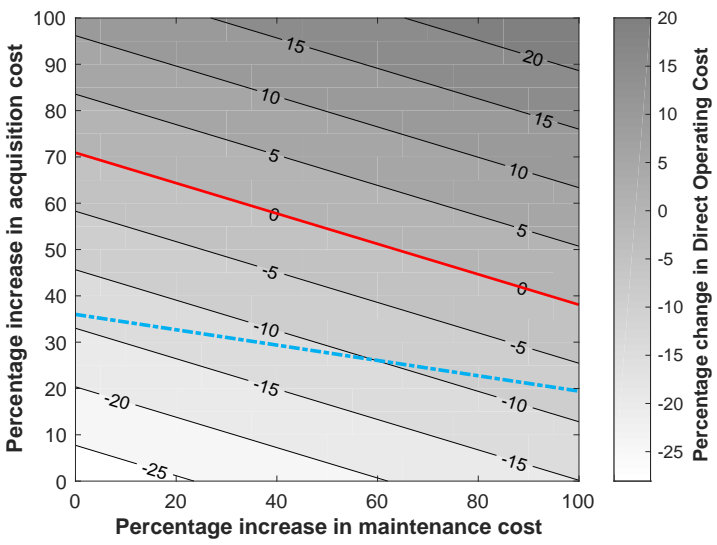

(a) $1.5 \times$ fuel price

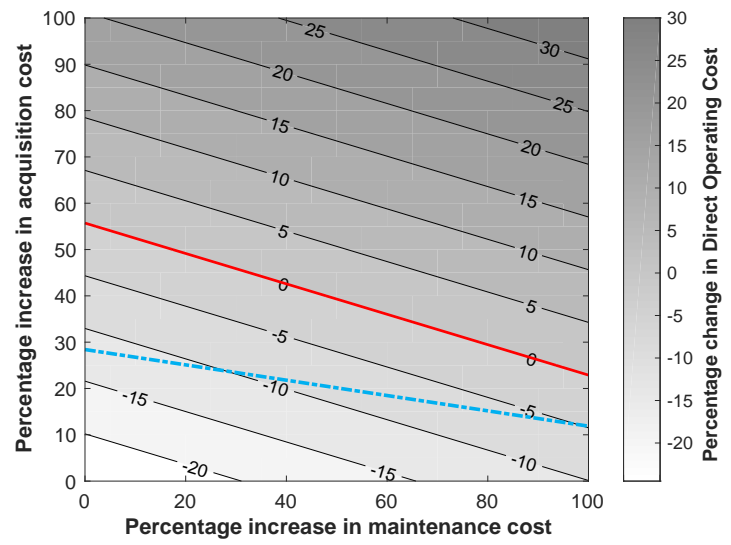

(b) Emissions tax $\left(\$ 30 /\right.$ short ton $\left.\mathrm{CO}_{2}\right)$

Figure 10: Sensitivity analysis for alternative scenarios (7500 nmi mission).

space of a one or two year period, based on previous oil price crashes and rises). Figure 10b considers a Carbon Dioxide taxation scenario, with a demonstrative levied tax of $\$ 30$ per short ton of $\mathrm{CO}_{2}$ emitted over the course of a flight (predicted cost of $\mathrm{CO}_{2}$ in 2035 [41]). The two alternative scenarios both increase the cost of operating a lower efficiency aircraft with higher energy usage. Hence, both options widen the margin for acquisition price and maintenance cost increases for an aircraft such as the N3-X, whilst still allowing for an economically viable design.

Due to the volatility of fuel price, predicting the future cost of fuel is a challenge, and price changes may be partially avoided in the short term by hedging the cost of fuel. Applying emissions taxation provides a more certain method for aviation bodies to encourage adoption of more environmentally friendly alternatives. The analysis suggests that the introduction of carbon taxation on aircraft emissions can be used to obtain a similar outcome to a change in fuel price (Figure 10).

An increase in the size of the economically viable region provides manufacturers with a greater margin for increases in acquisition price and maintenance cost, whilst still presenting an economically attractive aircraft. Nonetheless, the limited margins for increases in acquisition and maintenance cost in a low fuel price scenario create a challenging economic environment for the development of a novel aircraft. External encouragement such as emission taxation would encourage the development and purchase of high efficiency technology by increasing the cost saving offered by a high efficiency aircraft. This therefore decreases the risk that the aircraft cost would exceed the limits that define an economically viable concept. 


\subsubsection{Liquid Hydrogen N3-X}

As Liquid Hydrogen is not currently a commercially available fuel for the aviation industry as a primary fuel source, it becomes difficult to predict the operating costs associated with the aircraft. However, with a number of sources available for the production of Liquid Hydrogen, there is the potential for lower price volatility in $\mathrm{LH}_{2}$ fuel price compared to kerosene. Additionally, given suitable investment, a low cost production method might be established. In terms of fuel mass used, the $\mathrm{LH}_{2} \mathrm{~N} 3-\mathrm{X}$ would burn $10 \%$ of the fuel mass of the baseline aircraft for a $7500 \mathrm{nmi}$, due to the high energy density by mass of hydrogen. If $\mathrm{LH}_{2}$ fuel price per unit mass were able to equal that of kerosene, the possibility for a significantly lower cost of fuel is established. The future cost of liquid hydrogen as an aviation fuel is unknown, particularly if industry focus towards developing alternative fuels. An initial estimate of the fuel price of $\mathrm{LH}_{2}$ was made based on targets for hydrogen production. This establishes a price point of $\$ 2.00$ per kilogram $\mathrm{LH}_{2}$ (target for 2020, $\mathrm{LH}_{2}$ production through water electrolysis) [42]. It should be noted that current estimates for the price per kilogram $\mathrm{LH}_{2}$ are significantly higher at around $\$ 6.90$ per kilogram $\mathrm{LH}_{2}[42,43]$. Low fuel consumption by mass coupled with the introduction of a carbon tax on aviation (a factor which would have no influence on a non-hydrocarbon propulsion system), the potential for large operating cost savings becomes apparent.

In the first scenario, the assumed $\mathrm{LH}_{2}$ fuel price was used with no carbon taxation (Figure 11a). In the second scenario, a carbon tax of $\$ 30$ per short ton of $\mathrm{CO}_{2}$ emitted by the aircraft was reintroduced (Figure 11b). Due to a relatively high cost of fuel, the direct operating cost of the $\mathrm{LH}_{2} \mathrm{~N} 3-\mathrm{X}$ variant is higher than that of the kerosene N3-X, leading to a lower direct operating cost saving versus the baseline aircraft (Figure 7). As a result, the maximum viable cost of the $\mathrm{LH}_{2} \mathrm{~N} 3-\mathrm{X}$ is lower than the kerosene N3-X. However, in a taxation scenario, there is no $\mathrm{CO}_{2}$ tax charged for the $\mathrm{LH}_{2}$ aircraft as there are no carbon emissions. This therefore leads to a larger direct operating cost saving versus the baseline aircraft and hence a higher maximum viable cost. As with the kerosene aircraft, fuel is not the only contributing factor to operating costs. $\mathrm{A} \mathrm{LH} \mathrm{LH}_{2}$ aircraft has the potential for higher acquisition and maintenance costs introduced by factors such certification and safety requirements. Depending on the combination of these factors, the kerosene option may appear more viable from an economic perspective.

There is much uncertainty in the cost of $\mathrm{LH}_{2}$ as a commercial aviation fuel. However, it is possible to establish the fuel cost at which the direct operating cost of the $\mathrm{LH}_{2} \mathrm{~N} 3-\mathrm{X}$ matches that of the kerosene N3-X (Figure 12). As the energy usage of the two aircraft does not directly correspond, this price point depends on the mission range. Similarly, the price point will depend on the current price of kerosene. Assuming that the acquisition and maintenance cost of the two 


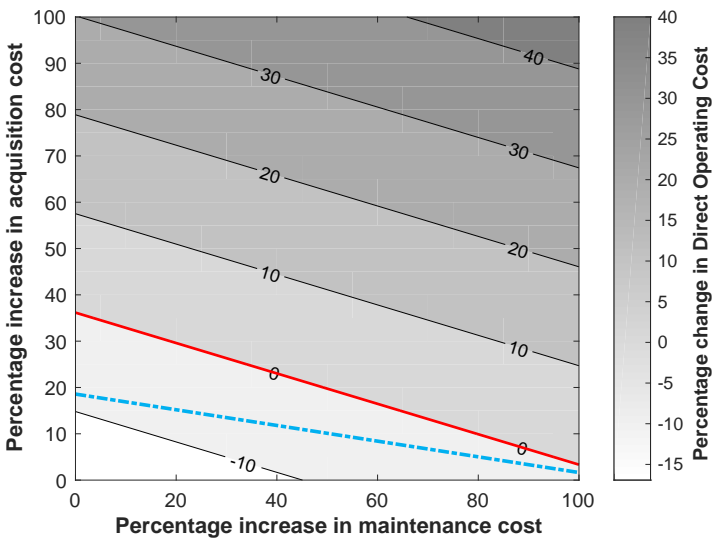

(a) $\$ 2.00$ per kilogram $\mathrm{LH}_{2}$

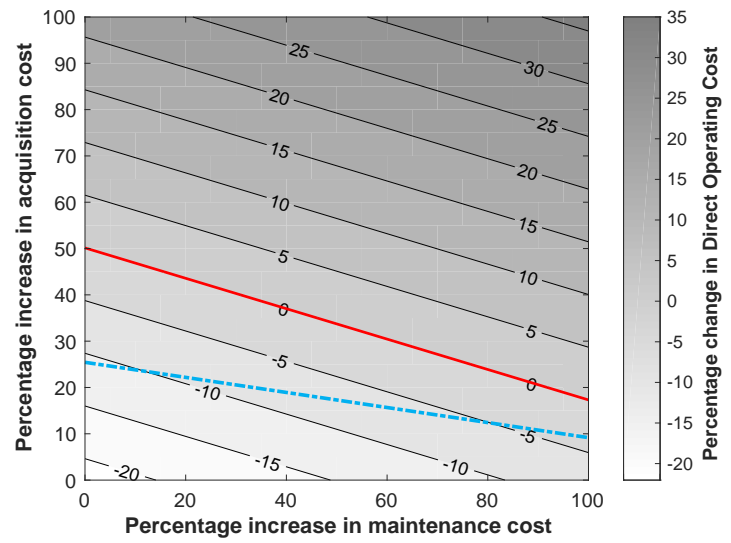

(b) Emissions tax $\left(\$ 30 /\right.$ tonne $\left.\mathrm{CO}_{2}\right)$

Figure 11: Direct operating cost sensitivity analysis for the kerosene N3-X in comparison to the baseline aircraft for different scenarios

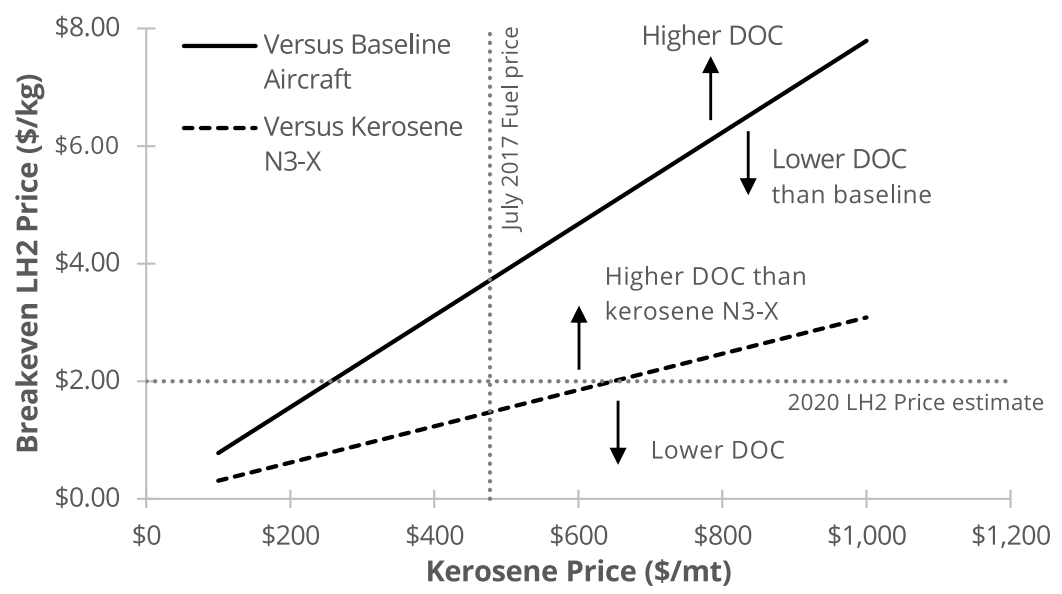

Figure 12: Liquid Hydrogen price point that matches direct operating cost of the $\mathrm{LH}_{2}$ and kerosene N3-X variants

variants was the same, the price of $\mathrm{LH}_{2}$ could be anywhere up to $\$ 1,470$ per metric tonne, whilst still operating at a lower cost than the kerosene variant (at the simulated kerosene price and for the design point $7500 \mathrm{nmi}$ mission). Introducing a carbon tax would increase the breakeven price per unit of $\mathrm{LH}_{2}$, as the difference in direct operating cost between a $\mathrm{LH}_{2}$ and kerosene aircraft would be greater.

\section{Conclusion}

The increased environmental awareness of today's aviation industry has been a key driver in the research and development of revolutionary new aircraft concepts. In order to encourage the development of a more sustainable industry, it is important to ensure that new technologies are profitable for operators. The research focuses on assessing whether aircraft that will be capable of achieving challenging environmental goals, whilst remaining economically viable in 
a commercial market. The present work has detailed the application of a techno-economic analysis framework for assessing the economic viability of NASA's N3-X, a blended wing body aircraft with a novel propulsion system. A sensitivity analysis has been presented that may offer insight to airlines and manufacturers as to the costs limits for a viable aircraft. It presents a 'map' of the cost region that manufacturers should target in order for the N3-X concept to remain economically attractive for operators. In addition, the research presents alternative policy or fuel options for the aircraft that may be used to incentivise the adoption of greener aircraft technology.

The results suggest that the N3-X has the potential to exceed the targeted fuel burn improvements for future aircraft set by NASA. This is evident in the simulation results, that suggest the aircraft will achieve a $60.4 \%$ energy savings versus the baseline aircraft for the design mission. However, further analysis would require be required to compare the performance relative to a suitable 2035 baseline in order to predict whether the benefits of revolutionary technologies are worth the investment cost over evolutionary technology. The increased fuel efficiency of the N3-X has the potential to translate into operating cost benefits, assuming aircraft costs can be kept low. For the design mission and a July 2017 fuel price, the aircraft must be no more than $24 \%$ more expensive than the baseline aircraft in order to remain economically attractive. Using the aircraft for short range missions (such as high capacity short-haul flights) results in an economic viability that is especially sensitive to changes in maintenance and acquisition costs. This suggests that the aircraft would not be suitable for such usage, although long range aircraft such as the B777-200LR are nonetheless occasionally used in such a role.

The results suggest that fuel cost contributes a small percentage to the total direct operating cost for a high efficiency aircraft such as the N3-X. Instead, factors related to ownership, especially purchase cost, contribute a significant amount to overall cost. Furthermore, maintenance cost have the potential to exceed fuel cost for the aircraft. As it is highly likely that a novel, complex aircraft such as the N3-X would be more expensive to purchase and maintain than equivalent conventional aircraft, ownership costs have a larger role than in the direct operating cost of conventional aircraft. It is possible that this may encourage operators to push for more efficient maintenance strategies or aircraft that are cheaper to maintain, in order to reduce the day-to-day operating cost of the aircraft. Alternatively, an increase in maintenance cost may be considered an acceptable trade-off for the overall operating cost benefits that could be provided by the higher efficiency aircraft. Nonetheless, it is possible that the reduced impact of fuel cost on DOC may redirect commercial focus from higher efficiency to lower ownership cost aircraft. However, from the investment cost analysis perspective, it is suggested that there is a greater 
benefit in attempting to reduce acquisition costs rather than maintenance costs. Acquisition costs have a much greater impact on DOC than maintenance. In addition, the cost of aircraft acquisition is a one-time value determined during the initial purchase of the aircraft, and cannot be modified after the fact.

An important point to note about the present analysis is that it represents the aviation industry economic climate consistent with the time. Should aviation fuel prices increase or an emissions tax be introduced, the economic benefits of the N3-X will become more apparent to potential customers. High fuel price or emissions taxation scenarios will provide an incentive for operators to move from older, less efficient aircraft to new green aircraft options and a more sustainable industry. Should fuel prices and the economic climate remain as assumed in this study, economic drivers would be necessary to encourage adoption of novel high efficiency aircraft such as the N3-X, unless costs can be kept close to the baseline levels.

\section{Acknowledgements}

The authors would like to extend their gratitude to NASA for making this work possible under grant number NNX13AI78G. Many thanks go also to staff at Cranfield University for their advice and assistance.

\section{References}

[1] Air Transport Action Group, Flightpath, 2013.

[2] W. Zhou, T. Wang, Y. Yu, D. Chen, B. Zhu, Scenario analysis of co2 emissions from chinas civil aviation industry through 2030, Applied Energy 175 (2016) 100-108.

[3] R. K. Goel, D. P. Rich, On the adoption of new technologies, Applied Economics 29 (4) (1997) 513-518.

[4] P. Clark, Buying the Big Jets: fleet planning for airlines, Ashgate Publishing, Ltd., 2007.

[5] W. D. Kristjanpoller, D. Concha, Impact of fuel price fluctuations on airline stock returns, Applied Energy 178 (2016) 496-504.

[6] D. N. Mavris, O. Bandte, D. A. DeLaurentis, Robust design simulation: a probabilistic approach to multidisciplinary design, Journal of Aircraft 36 (1) (1999) 298-307.

[7] L. Dray, A. Evans, T. Reynolds, A. W. Schäfer, M. Vera-Morales, W. Bosbach, Airline fleet replacement funded by a carbon tax: an integrated assessment, Transport Policy 34 (2014) 75-84. 
[8] R. Tam, P. Belobaba, K. R. Polenske, I. Waitz, Assessment of Silent Aircraft-Enabled Regional Development and Airline Economics in the UK, in: 45th AIAA Aerospace Sciences Meeting and Exhibit, Aerospace Sciences Meetings, Reno, NV, USA, no. AIAA 2007-455, 2007.

[9] H. A. Edwards, D. Dixon-Hardy, Z. Wadud, Aircraft cost index and the future of carbon emissions from air travel, Applied Energy 164 (2016) 553-562.

[10] D. K. Nalianda, K. G. Kyprianidis, V. Sethi, R. Singh, Techno-economic viability assessments of greener propulsion technology under potential environmental regulatory policy scenarios, Applied Energy 157 (2015) 35-50.

[11] L. Newnes, A. Mileham, W. M. Cheung, R. Marsh, J. Lanham, M. Saravi, R. Bradbery, Predicting the whole-life cost of a product at the conceptual design stage, Journal of Engineering Design 19 (2) (2008) 99-112.

[12] James L. Felder and Hyun Dae Kim and Gerald V. Brown, Turboelectric distributed propulsion engine cycle analysis for hybrid-wing-body aircraft, in: 47th AIAA Aerospace Sciences Meeting Including The New Horizons Forum and Aerospace Exposition, Orlando, FL, USA, no. AIAA 2009-1132, 2009.

[13] J. L. Felder, G. V. Brown, H. D. Kim, J. Chu, Turboelectric Distributed Propulsion in a Hybrid Wing Body Aircraft, in: 20th ISABE Conference, Gothenburg, Sweden, no. ISABE-20111340, 2011.

[14] T. Donateo, L. Spedicato, Fuel economy of hybrid electric flight, Applied Energy 206 (2017) 723-738.

[15] E. Baharozu, G. Soykan, M. B. Ozerdem, Future aircraft concept in terms of energy efficiency and environmental factors, Energy 140 (2017) 1368-1377.

[16] J. S. Fuglestvedt, K. P. Shine, T. Berntsen, J. Cook, D. Lee, A. Stenke, R. B. Skeie, G. Velders, I. Waitz, Transport impacts on atmosphere and climate: Metrics, Atmospheric Environment 44 (37) (2010) 4648-4677.

[17] R. Peters, R. Samsun, Evaluation of multifunctional fuel cell systems in aviation using a multistep process analysis methodology, Applied energy 111 (2013) 46-63.

[18] S. Blakey, L. Rye, C. W. Wilson, Aviation gas turbine alternative fuels: A review, Proceedings of the combustion institute 33 (2) (2011) 2863-2885. 
[19] S. Ogaji, P. Pilidis, R. Hales, TERA-a tool for aero-engine modelling and management, in: 2nd World Congress on Engineering Asset Management and 4th International Conference on Condition Monitoring, Harrogate, UK, 2007.

[20] I. Goulos, V. Pachidis, C. Celis, R. D'Ippolito, J. Stevens, Simulation Framework Development for Aircraft Mission Analysis, in: ASME Turbo Expo 2010: Power for Land, Sea, and Air, no. GT2010-23379, 2010.

[21] G. Doulgeris, T. Korakianitis, P. Pilidis, E. Tsoudis, Techno-economic and environmental risk analysis for advanced marine propulsion systems, Applied Energy 99 (2012) 1-12.

[22] E. Najafi Saatlou, K. Kyprianidis, V. Sethi, A. Abu, P. Pilidis, On the Trade-Off Between Minimum Fuel Burn and Maximum Time Between Overhaul for an Intercooled Aeroengine, Proceedings of the Institution of Mechanical Engineers, Part G: Journal of Aerospace Engineering 228 (2014) 2424-2438.

[23] K. G. Kyprianidis, T. Grönstedt, S. O. Ogaji, P. Pilidis, R. Singh, Assessment of future aeroengine designs with intercooled and intercooled recuperated cores, Journal of Engineering for Gas Turbines and Power 133 (2011) 1-10.

[24] K. G. Kyprianidis, A. M. Rolt, T. Grönstedt, Multidisciplinary Analysis of a Geared Fan Intercooled Core Aero-Engine, Journal of Engineering for Gas Turbines and Power 136 (1) (2014) 011203.

[25] J. L. Felder, H. D. Kim, G. V. Brown, J. Chu, An examination of the effect of boundary layer ingestion on turboelectric distributed propulsion systems, in: 49th AIAA Aerospace Sciences Meeting including the New Horizons Forum and Aerospace Exposition, Orlando, FL, USA, 2011.

[26] C. Goldberg, D. Nalianda, P. Pilidis, R. Singh, Performance Assessment of a Boundary Layer Ingesting Distributed Propulsion System at Off-Design, in: 53rd AIAA/SAE/ASEE Joint Propulsion Conference, 2017, alAA 2017-5055.

[27] W. Macmillan, Development of a modular-type computer program for the calculation of gas turbine off-design performance, Ph.D. thesis, Cranfield University (1974).

[28] P. Giannakakis, P. Laskaridis, T. Nikolaidis, A. I. Kalfas, Toward a scalable propeller performance map, Journal of Propulsion and Power 31 (4) (2015) 1073-1082.

[29] Jane's Aero-engines, Jane's Information Group, 2015. 
[30] C. Goldberg, D. Nalianda, P. Pilidis, D. MacManus, J. Felder, Installed Performance Assessment of a Boundary Layer Ingesting Distributed Propulsion System at Design Point, in: 52nd AIAA/SAE/ASEE Joint Propulsion Conference, 2016, aIAA 2016-4800.

[31] Boeing, B777 Technical Characteristics, accessed: October 2014. URL http://www.boeing.com/commercial/777/

[32] Jane's All the World's Aircraft, McGraw-Hill, 2016.

[33] M. Moore, NASA N3-X Concept Model, accessed: July 2014. URL http://hangar.openvsp.org/vspfiles/59

[34] P. R. Sekaran, A. S. Gohardani, G. Doulgeris, R. Singh, Liquid hydrogen tank considerations for turboelectric distributed propulsion, Aircraft Engineering and Aerospace Technology 86 (1) (2013) 67-75.

[35] A. J. Colozza, Hydrogen storage for aircraft applications overview, Tech. Rep. NASA/CR2002-211867 (2002).

[36] D. P. Raymer, Aircraft Design: A Conceptual Approach, AIAA, 2006.

[37] IATA, Economic Performance of the Airline Industry: Mid 2017, accessed: June 2017 (2017).

URL http://www.iata.org/whatwedo/Documents/economics/IATA-Economic-Performance-of-the-I

[38] S. Lumby, Investment appraisal and financing decisions, Chapman \& Hall, 1991.

[39] Aircraft Commerce, Owners and Operators Guide: 777-200/-300 60 (2008) 6-30.

[40] Aircraft Commerce, Head to Head: A330/340 versus the 777-200/-300 17 (2001) 16-24.

[41] P. Luckow, E. A. Stanton, S. Fields, B. Biewald, S. Jackson, J. Fisher, R. Wilson, Carbon Dioxide Price Forecast, Synapse Energy Economics, 2015.

[42] US Department of Energy - Fuel Cell Technologies Office, Multi-year research, development, and demonstration plan - hydrogen production, accessed: March 2017.

[43] P. Stadler, Cost evaluation of large scale hydrogen production for the aviation industry, Master's thesis, Ecole Polytechnique Fédérale de Lausanne (2014). 
2018-04-17

\section{Assessment of an energy-efficient} aircraft concept from a techno-economic perspecti

\section{Goldberg, Chana}

\section{Elsevier}

Goldberg C, Nalianda D, Sethi V, et al., (2018) Assessment of an energy-efficient aircraft concept from a techno-economic perspective. Applied Energy, Volume 221, Issue 1, July 2018, pp. 229-238

http://dx.doi.org/10.1016/j.apenergy.2018.03.163

Downloaded from Cranfield Library Services E-Repository 